\section{Papaya Seedling Growth Response to Wind and Water Deficit is Additive}

\author{
Thomas E. Marler ${ }^{1}$ and Hiphil S. Clemente \\ Agricultural Experiment Station, College of Natural and Applied Sciences, \\ University of Guam, Mangilao, Guam 96923
}

Additional index words. Carica papaya, multiple stress interaction, water deficits, wind stress

\begin{abstract}
Trade winds occur throughout the year and drought occurs seasonally in many papaya (Carica papaya $L$.) production regions. We conducted four studies with 'Known You 1' and 'Sunrise' papaya seedlings to determine the combined influence of wind and water deficit on growth. We conducted three additional experiments to determine plant response to wind within a continuous dose range of 0 to $2.5 \mathrm{~m} \cdot \mathrm{s}^{-1}$. The main effects of wind and irrigation significantly reduced most response variables, such as dry weight components, leaf area, and height. However, the two factors acted independently of each other for every measure of plant growth. Thus, there was no departure from simple effects of an additive model for each main factor. The relationship between plant growth and wind between 0 and $2.5 \mathrm{~m} \cdot \mathrm{s}^{-1}$ could be described by a quadratic model. Results indicate that the influence of wind on plant growth cannot be studied without controlling or quantifying soil moisture among treatment groups. Practically, our results indicate that wind protection of young papaya plants may be warranted more so in the dry season than in the wet season or under sufficient irrigation practices.
\end{abstract}

Wind exposure reduces growth and yield of numerous horticultural crops (Waister, 1972). Most information on the influence of wind on papaya is general in nature and not based on empirical studies (e.g., Malo and Campbell, 1994; Nakasone and Paull, 1998; Samson, 1980). We have recently reported the only published data that we are aware of on this subject (Clemente and Marler, 2001). Various measures of growth of three papaya cultivars were decreased by exposure to wind. Moreover, wind exposure increased dark respiration and decreased net photosynthesis of papaya leaves when compared with wind protection(Clemente and Marler, 2001).

Water deficits affect plant development in many ways such as reduced growth and altered patterns of resource allocation (Nilsen and Orcutt, 1996). For example, water deficits generally increase root growth relative to stem and leaf growth (Brouwer, 1983; Nilsen and Orcutt, 1996; Russell, 1977). Published information on the responses of papaya plants to water stress is minimal. In one study, drought stress reduced net photosynthesis, altered the diurnal pattern of gas exchange, and decreased various measures of photochemical efficiency of papaya plants (Marler and Mickelbart, 1998). In another study, the speed with which stomata were able to track rapid changes in irradiance was compromised by water deficits (Clemente and Marler, 1996).

Plants are rarely exposed to a single environmental stress (Mooney et al., 1991). Thus, the effect of wind on plants may vary with water availability, and plant response to water deficits may vary with wind exposure. We conducted preliminary experiments to learn that wind and

Received for publication 28 Sept. 2005. Accepted for publication 13 Oct. 2005. Support provided by USDA CSREES Special Grant in Tropical/Subtropical Agricultural Research, administered by PBAG.

'Corresponding author; e-mail tmarler@uog9. uog.edu. drought reduced papaya growth independently when provided in combination (Clemente and Marler, 1999). The number of replications in those studies was low due to limitations in the experimental arrangement. We know of no other reports on the influence of the interaction of these two important environmental stresses on papaya. Thus, the purpose of this study was to conduct a series of experiments to determine the combined influence of wind and irrigation on papaya plants using an adequate number of replications. We predicted the negative growth responses to wind or water deficit would be exacerbated by a combination of both factors.

Additionally, the only published data on papaya response to wind used disjunct levels of wind exclusion (Clemente and Marler, 2001). Plants were exposed to no wind or reduced wind by use of plastic or screen baffles. This did not allow for any discussion about the influence of wind speed as the continuous variable that it is. Thus, a secondary purpose of this study was to define papaya growth response to a continuous range of wind speed. We predicted a segmented model similar to plant response to salinity stress (e.g., van Genuchten and Hoffman, 1984) would result where growth at low wind speeds would result in a plateau, and growth would begin to decline as wind increased beyond a threshold wind speed.

\section{Materials and Methods}

In total, seven experiments were conducted in 2002 and 2003 using industrial fans to supply wind and a constructed rain shed to protect the experimental site from rainfall. The number of plants that could be adequately exposed to prescribed wind treatments was limited by the experimental layout. Thus, we elected to conduct a series of short-term experiments then subject results to combined analysis of variance to achieve an adequate number of replications.

Experiments 1 to 4 . Four experiments were conducted to determine the combined influence of irrigation and wind on papaya seedlings. For each study, 'Known You 1' and 'Sunrise' papaya seeds were planted in 0.625 -L pots with a growing medium consisting of $60 \%$ peat and $40 \%$ perlite. The seedlings were grown under nursery conditions for 3 weeks, and irrigated as needed. Plants were fertilized weekly with $25 \mathrm{~mL}$ of complete fertilizer solution (Excel, Grace-Sierra, Milpitas, Calif.) providing 7.5 $\mathrm{mM}$ N. Eighteen plants that were homogeneous in height and stem diameter were selected from each cultivar, and six of these were randomly selected and dried to constant weight at $70{ }^{\circ} \mathrm{C}$ to determine initial dry weight.

The remaining 12 seedlings from each cultivar were transferred to the experimental area. Initial plant height was measured. The experiment was conducted on nursery benches under a clear polypropylene cover. The structure allowed $92 \%$ sunlight transmission but prevented the exposure to rain. The sides of the structure were kept uncovered.

Six seedlings of each cultivar were exposed to unidirectional wind averaging $2.0 \mathrm{~m} \cdot \mathrm{s}^{-1}$ for $12 \mathrm{~h}$ during each photoperiod for 3 weeks. Plants were subjected to wind treatments during the photoperiod because historic information evinces a disparity in diurnal and nocturnal wind average (Clemente and Marler, 2001, and citations therein). Wind was supplied by three industrial fans, and the affected bench area could only accommodate 12 plants in a manner that ensured homogeneity of wind speed and lack of mutual protection from wind. The remainder of the seedlings were placed away from the fans as the control (no wind). Half of the wind-exposed seedlings and half of those not exposed to wind were subjected to reduced water supply. We initiated this treatment by weighing each plant to determine $24 \mathrm{~h}$ water use, then adding back half of that amount. This continued for the first week, and $25 \mathrm{~mL}$ was added to each container each day thereafter. The remaining plants were watered daily to maintain rooting substrate near container capacity. This approach provided treatments of wind and water deficit, wind and adequate irrigation, no wind and water deficit, and no wind and adequate irrigation. There were three replications for each treatment combination for each of the four experiments, for a total of 12 replications for each treatment combination for combined analysis of repeated experiments.

Final measurements included stem height, stem base diameter, and leaf area (LA) (model AM 100 area meter; Analytical Development Co., Hoddesdon, Herts, U.K.). Leaf, stem, and root dry weights were measured after drying to a constant weight at $70^{\circ} \mathrm{C}$. Growth in terms of increase in dry weight, increase in height, and root-canopy ratio (RCR) were calculated. Relative growth rate (RGR) was calculated as the change in dry weight over the change in time per unit final dry weight. Stem cross sectional area (SCA) was calculated from the measured stem diameter. Specific leaf area (SLA) was calculated as leaf area divided by leaf weight.

Experiments 5 to 7 . Preparation of plant material followed methods described above. Three-week-old seedlings were placed in the 
experimental area in a manner that allowed exposure to wind speeds within the range of 0 to $2.5 \mathrm{~m} \cdot \mathrm{s}^{-1}$. We limited exposure to wind to $12 \mathrm{~h}$ during the photoperiod. As with Expts. 1 to 4 , we were constrained by the experimental arrangement and the need to ensure a lack of mutual wind protection among the plants. Thus, the experiment was repeated for a total of three experiments.

Statistical analysis. We did not desire to compare cultivar differences, so we analyzed data for each cultivar separately. The results from Expts. 1 to 4 were analyzed as a combined analysis of variance over four experiments (Gomez and Gomez, 1984) in order to remove the variation among experiments from the error term. The analysis was based on a two-way factorial with wind and irrigation as the factors within each experiment. The increase in plant height, dry weight (leaf, stem, root, and total), LA, SCA, RGR, RCR, and SLA were our response variables. We treated the increase in dry weight in Expts. 5 to 7 as the dependent variable, and wind speed as the independent variable. These data were fitted with various functions to determine if this response was best described by a segmented model or a smooth function (SAS Institute, 1988).

\section{Results}

Experiments 1 to 4 . The main effect of wind exposure influenced every response variable for 'Sunrise' (Table 1) and every response variable except for LA and RCR for 'Known You 1 ' (Table 2). All significant direct measures of plant growth or plant size were decreased by wind exposure, as was the calculated RGR. In contrast, SLA was greater for wind-exposed plants than for protected plants.

Our intention for the irrigation treatment was to impose a slowly developing level of water deficit rather than an acute stress, since our primary objective was to study the interaction with wind. The decrease in RGR due to water deficit was similar to the decrease in RGR due to wind exposure. Thus, we believe the methods achieved the desired outcome. The main effect of irrigation influenced response variables in a manner similar to wind (Tables 1 and 2). RCR of 'Known You 1' plants was not influenced by irrigation.

The interaction of wind and irrigation is the focus of this study. None of the measures of plant growth or size were influenced by the interaction of wind and irrigation (Tables 1 and 2). In contrast, the interaction of these two factors significantly influenced SLA of 'Sunrise' seedlings (Table 1). Under the conditions of this study, water deficit decreased SLA less in wind-exposed plants than in protected plants. Similarly, wind decreased SLA less in plants exposed to water deficit than in wellwatered plants.

Experiments 5 to 7 . The increase in dry weight of papaya seedlings as influenced by exposure to a wind speed continuum was not described by a segmented model as we predicted. The decline in growth was smooth throughout the wind range of 0 to $2.5 \mathrm{~m} \cdot \mathrm{s}^{-1}$ for both cultivars. Both response curves could be explained with a negative quadratic function (Fig. 1).

\section{Discussion}

Plant responses to wind and the factors that define those responses are complex (reviewed by Grace, 1977; Ennos, 1997). Attempts at generalizing plant responses are usually misleading (e.g., Smith and Ennos, 2002). The influence of wind on plants may vary with duration and velocity (Grace, 1977; Kramer and Kozlowski, 1979; Nobel, 1981); plant species (Davies et al., 1974), plant density (Retuerto et al., 1996), shade level (Henry and Thomas, 2002), and leaf $\times$ air interactions (Grace, 1977; Mansfield and Davies, 1985). Studying any negative aspects of wind is also confusing because wind-induced mechanical stimulation of plants elicits beneficial responses, such as improved pest resistance (Cipollini, 1997) and improved biomechanical properties of roots (e.g., Stokes et al., 1995; Tamasi et al., 2005) or stems (e.g., Watt et al., 2005) leading to increased plant stability.

Wind and seasonal drought are two environmental stresses that influence growth and development of many tropical and subtropical horticultural species. Our results confirm that the relative level of water deficit or irrigation is another factor to consider when studying and interpreting plant responses to wind. For young papaya seedlings in this controlled study area, wind and irrigation acted independently of each other for every measure of plant growth. However, the main effects of wind and irrigation were significant for a majority of the variables. Thus, there was no departure from simple effects of an additive model for each main factor. When these stresses occur simultaneously, plants may respond to a greater degree than when either stress is imposed alone.

Drought stress has modified the effects of wind exposure for other species. Heiligmann

Table 1. The response of 'Sunrise' papaya seedlings to $12 \mathrm{~h} \cdot \mathrm{d}^{-1}$ of $2 \mathrm{~m} \cdot \mathrm{s}^{-1}$ wind exposure and irrigation level. Variables were leaf dry weight (LDW), stem dry weight (SDW), root dry weight (RDW), total dry weight (TDW), total plant leaf area (LA), root to canopy ratio (RCR), increase in stem height, stem crosssectional area (SCA), specific leaf area (SLA), and relative growth rate (RGR).

\begin{tabular}{|c|c|c|c|c|c|c|c|}
\hline \multirow[b]{2}{*}{ Variable } & \multicolumn{2}{|c|}{ Wind exposure } & \multicolumn{2}{|c|}{ No wind } & \multicolumn{3}{|c|}{$P$ value } \\
\hline & $\begin{array}{c}\text { High } \\
\text { irrigation }\end{array}$ & $\begin{array}{c}\text { Low } \\
\text { irrigation }\end{array}$ & $\begin{array}{c}\text { High } \\
\text { irrigation }\end{array}$ & $\begin{array}{c}\text { Low } \\
\text { irrigation }\end{array}$ & $\begin{array}{l}\text { Wind } \\
\text { (W) }\end{array}$ & $\begin{array}{l}\text { Irrigation } \\
\text { (I) }\end{array}$ & $\mathrm{W} \times \mathrm{I}$ \\
\hline LDW (mg) & 569 & 309 & 708 & 442 & 0.0003 & 0.0001 & 0.8817 \\
\hline SDW (mg) & 275 & 193 & 308 & 275 & 0.0116 & 0.0078 & 0.2961 \\
\hline RDW (mg) & 772 & 656 & 1538 & 1144 & 0.0001 & 0.0008 & 0.0580 \\
\hline TDW (mg) & 1615 & 1158 & 2554 & 1861 & 0.0001 & 0.0001 & 0.2583 \\
\hline $\operatorname{LA}\left(\mathrm{cm}^{2}\right)$ & 162 & 107 & 210 & 136 & 0.0008 & 0.0001 & 0.3905 \\
\hline RCR & 0.98 & 1.49 & 1.55 & 1.74 & 0.0014 & 0.0050 & 0.2028 \\
\hline Height (cm) & 11.7 & 8.1 & 13.4 & 10.9 & 0.0007 & 0.0001 & 0.3751 \\
\hline $\mathrm{SCA}\left(\mathrm{mm}^{2}\right)$ & 33.4 & 28.3 & 45.3 & 37.9 & 0.0001 & 0.0005 & 0.4521 \\
\hline $\operatorname{SLA}\left(\mathrm{cm}^{2} \cdot \mathrm{mg}^{-1}\right)$ & 0.28 & 0.36 & 0.29 & 0.31 & 0.0372 & 0.0001 & 0.0014 \\
\hline RGR $\left(g \cdot g^{-1} \cdot\right.$ week $\left.^{-1}\right)$ & 0.30 & 0.28 & 0.30 & 0.28 & 0.0038 & 0.0001 & 0.5947 \\
\hline
\end{tabular}

Table 2. The response of 'Known You 1' papaya seedlings to $12 \mathrm{~h} \cdot \mathrm{d}^{-1}$ of $2 \mathrm{~m} \cdot \mathrm{s}^{-1}$ wind exposure and irrigation level. Variables were leaf dry weight (LDW), stem dry weight (SDW), root dry weight (RDW), total dry weight (TDW), total plant leaf area (LA), root to canopy ratio (RCR), increase in stem height, stem cross-sectional area (SCA), specific leaf area (SLA), and relative growth rate (RGR).

\begin{tabular}{|c|c|c|c|c|c|c|c|}
\hline \multirow[b]{2}{*}{ Variable } & \multicolumn{2}{|c|}{ Wind exposure } & \multicolumn{2}{|c|}{ No wind } & \multicolumn{3}{|c|}{$P$ value } \\
\hline & $\begin{array}{l}\text { High } \\
\text { irrigation }\end{array}$ & $\begin{array}{c}\text { Low } \\
\text { irrigation }\end{array}$ & $\begin{array}{l}\text { High } \\
\text { irrigation }\end{array}$ & $\begin{array}{c}\text { Low } \\
\text { irrigation }\end{array}$ & $\begin{array}{l}\text { Wind } \\
\text { (W) }\end{array}$ & $\begin{array}{l}\text { Irrigation } \\
\text { (I) }\end{array}$ & $\mathrm{W} \times \mathrm{I}$ \\
\hline$\overline{\mathrm{LDW}}(\mathrm{mg})$ & 611 & 338 & 675 & 447 & 0.0217 & 0.0001 & 0.5325 \\
\hline SDW (mg) & 266 & 165 & 303 & 219 & 0.0314 & 0.0001 & 0.6917 \\
\hline RDW (mg) & 1017 & 703 & 1377 & 975 & 0.0020 & 0.0005 & 0.6449 \\
\hline TDW (mg) & 1894 & 1206 & 2355 & 1641 & 0.0020 & 0.0001 & 0.9218 \\
\hline $\operatorname{LA}\left(\mathrm{cm}^{2}\right)$ & 180 & 114 & 192 & 139 & 0.0998 & 0.0001 & 0.5322 \\
\hline RCR & 1.17 & 1.39 & 1.40 & 1.46 & 0.1653 & 0.2028 & 0.4351 \\
\hline Height (cm) & 9.9 & 7.5 & 11.3 & 10.0 & 0.0001 & 0.0001 & 0.1827 \\
\hline $\operatorname{SCA}\left(\mathrm{mm}^{2}\right)$ & 32.3 & 19.3 & 34.5 & 28.4 & 0.0028 & 0.0001 & 0.0588 \\
\hline $\operatorname{SLA}\left(\mathrm{cm}^{2} \cdot \mathrm{mg}^{-1}\right)$ & 0.30 & 0.34 & 0.29 & 0.31 & 0.0005 & 0.0001 & 0.1198 \\
\hline RGR $\left(g \cdot g^{-1} \cdot\right.$ week $\left.^{-1}\right)$ & 0.28 & 0.25 & 0.30 & 0.28 & 0.0114 & 0.0012 & 0.2690 \\
\hline
\end{tabular}




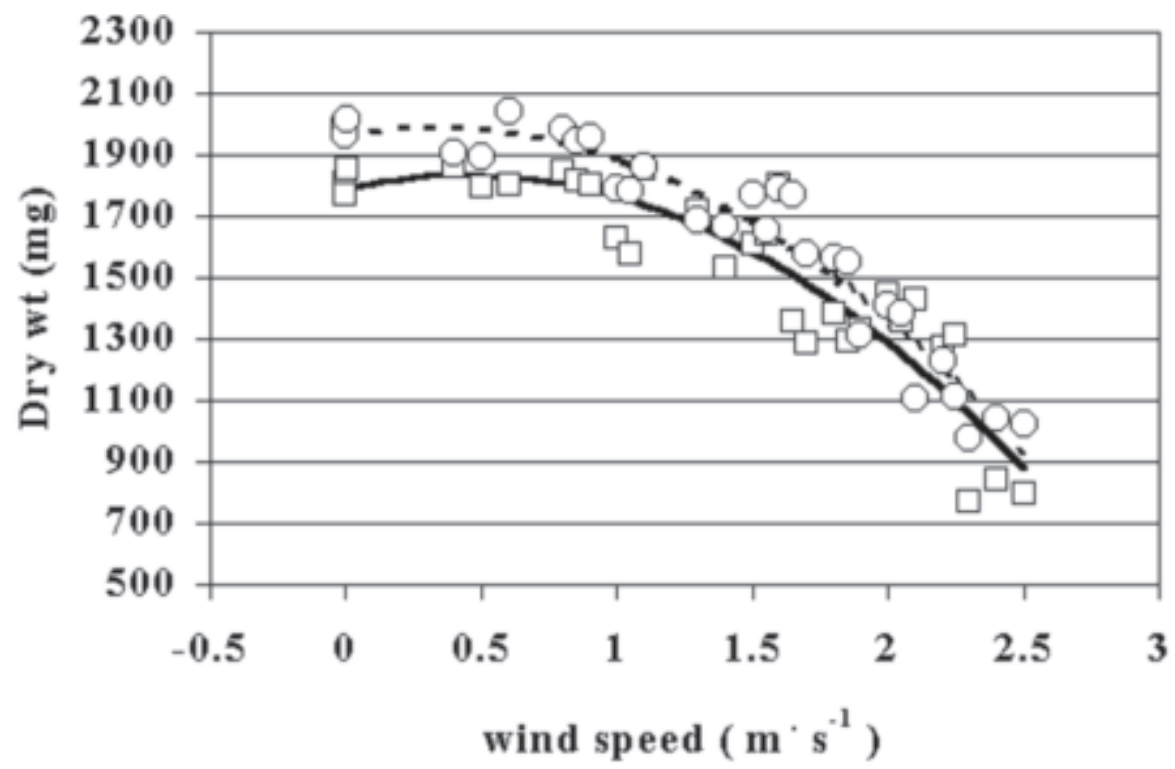

Fig. 1. The increase in dry weight of papaya seedlings during 3 weeks of wind exposure. Response equations were dry weight $=1967+150 \mathrm{x}-226 \mathrm{x}^{2}\left(P=0.0001, r^{2}=0.93\right.$, 'Sunrise', circles, dashed line $)$ and dry weight $=1792+203 \mathrm{x}-227 \mathrm{x}^{2}\left(P=0.0001, r^{2}=0.83\right.$, 'Known You 1', squares, solid line $)$.

and Schneider (1974) and Satoo (1962) reported that Juglans nigra L. and Robinia pseudoacacia L. growth declined more when drought was added to wind stress than when plants were exposed to wind under well-watered conditions. Grace and Russell (1982) also demonstrated wind and dry soil reduced leaf area and leaf water potential in Festuca arundinacea Schreb. more so than wind and well-watered soil. Retuerto and Woodward (1993) studied the influence of wind on Sinapis alba L. in controlled chambers. In those conditions, unrestricted water supply ameliorated the reduction in growth caused by wind stress. Moreover, they reported wind and water level influenced water use efficiency interactively. Since our growth response variables were additive and not interactive, further study is needed to determine if physiological responses to wind and drought are generally more inclined to be under an interactive influence than growth responses.

Papaya plant growth was decreased by wind speeds $<2 \mathrm{~m} \cdot \mathrm{s}^{-1}$ in this study. Similarly, growth of carambola (Averrhoa carambola L.) plants exposed to wind within the same speed range was reduced (Marler and Zozor, 1992). Plant age may influence the magnitude of response to these low wind doses, since age is one plant factor that influences response to wind (Clemente and Marler, 2001; Retuerto and Woodward, 1993). We did not find a threshold wind speed below which no growth reduction occurred, but this may have been due to the absence of wind dose levels below $0.5 \mathrm{~m} \cdot \mathrm{s}^{-1}$. Perhaps very low wind doses below this level could allow for the fitting of a segmented response model.

In conclusion, trade winds occur year round and drought occurs seasonally on Guam and other papaya production regions. When supplied in combination, these two stresses are independent, positive, and additive. From a research viewpoint, our data indicate that irrigation or soil moisture must be quantified or

controlled to accurately quantify plant response to wind stress. Similarly, the exposure to wind among treatment groups must be quantified or controlled in field irrigation studies for methods to be valid. From a horticultural viewpoint, our results indicate that wind protection of young papaya plants may be more critical in the dry season than in the wet season for rain-fed production systems. Conversely, for irrigated production systems, appropriate control over irrigation scheduling may be more important for young papaya plants grown without wind protection.

\section{Literature Cited}

Brouwer, R. 1983. Functional equilibrium: Sense or nonsense? Neth. J. Agr. Sci. 31:335-348.

Cipollini, Jr. D.F. 1997. Wind-induced mechanical stimulation increases pest resistance in common bean. Oecologia 111:84-90.

Clemente, H.S. and T.E. Marler. 1996. Drought stress influences gas-exchange responses of papaya leaves to rapid changes in irradiance. J. Amer. Soc. Hort. Sci. 121:292-295.

Clemente, H.S. and T.E. Marler. 1999. Growth of papaya seedlings under wind load and drought stress. HortScience 34:484 (abstr.).

Clemente, H.S. and T.E. Marler. 2001. Trade winds reduce growth and influence gas exchange patterns in papaya seedlings. Ann. Bot. 88:379-385

Davies, W.J., T.T. Kozlowski, and J. Pereira. 1974. Effects of wind on transpiration and stomatal aperture of woody plants, p. 433-438. In: Mechanisms of regulation of plant growth. Bul. 12. Royal Soc. of N.Z., Wellington.

Ennos, A.R. 1997. Wind as an ecological factor. Trends Ecol. Evol. 12:108-111.

Gomez, K.A. and A.A. Gomez. 1984. Statistical procedures for agricultural research. 2nd ed. Wiley \& Sons, New York.

Grace, J. 1977. Plant response to wind. Academic Press, New York.

Grace, J. and G. Russell. 1982. The effect of wind and a reduced supply of water on the growth and water relations of Festuca arundinacea Schreb. Ann. Bot. 49:217-225.
Heiligmann R. and G. Schneider. 1974. Effects of wind and soil moisture on black walnut seedlings. For. Sci. 20:331-335.

Henry, H.A. and S.C. Thomas. 2002. Interactive effects of lateral shade and wind on stem allometry, biomass allocation, and mechanical stability in Abutilon theophrasti (Malvaceae) Amer. J. Bot. 89:1609-1605.

Kramer, P.J. and T.T. Kozlowski. 1979. Physiology of woody plants. Academic Press, New York.

Malo, S.E. and C.W. Campbell. 1994. The papaya. Fla. Coop. Ext. Serv. Fact Sheet HS-11.

Mansfield, T.A. and W.J. Davies. 1985. Mechanisms for leaf control of gas exchange. BioScience $35: 158-164$

Marler, T.E. and M.V. Mickelbart. 1998. Drought, leaf gas exchange, and chlorophyll fluorescence of field-grown papaya. J. Amer. Soc. Hort. Sci. 123:714-718.

Marler, T. E. and Y. Zozor. 1992. Carambola growth and leaf gas-exchange responses to seismic or wind stress. HortScience 27:913-915.

Mooney, H.A., W.E. Winner, and E.J. Pell (eds.). 1991. Response of plants to multiple stresses. Academic Press, San Diego, Calif.

Nakasone, H.Y. and R.E. Paull. 1998. Tropical Fruits. CAB International, New York.

Nilsen, E.T. and D.M. Orcutt. 1996. The physiology of plants under stress. John Wiley and Sons, New York.
Nobel, P.S. 1981. Wind as an ecological factor, p. 475-500. In: Physiological plant ecology vol. 12-A.

Retuerto, R., L. Rochefort, and F.I. Woodward. 1996. The influence of plant density on the responses of Sinapis alba to $\mathrm{CO}_{2}$ and windspeed. Oecologia 108:241-251.

Retuerto, R. and F.I. Woodward. 1993. The influences of increased $\mathrm{CO}_{2}$ and water supply on growth, biomass allocation and water use efficiency of Sinapis alba L. grown under different wind speeds. Oecologia 94:415-427.

Russell, R.S. 1977. Relationship between roots and Shoots, p. 9-27. In: M.B. Wilkins (ed.). Plant root systems: Their function and interaction of the soil. McGraw-Hill Book Co., London.

Samson, J.A. 1980. Tropical fruits. Longman, New York.

SAS Institute. 1988. SAS/STAT user's guide, Release 6.03 edition. SAS Inst., Inc., Cary, N.C.

Satoo, T. 1962. Wind, transpiration, and tree growth, p. 299-310. In: T.T. Kozlowski (ed.). Tree growth. The Ronald Press, New York.

Smith, V.C. and A.R. Ennos. 2002. The effects of air flow and stem flexure on the mechanical and hydraulic properties of the stems of sunflowers Helianthus annuus L. J. Expt. Bot. 54:845-849. Responses of young trees to wind and shading: Effects on root architecture. J. Expt. Bot. 46:1139-1146.

Tamasi, E., A. Stokes, B. Lasserre, F. Danjon, S. Berthier, T. Fourcaud, and D. Chiantante. 2005. Influence of wind loading on root system development and architecture in oak (Quercus robur L.) seedlings. Trees 19:374-384.

van Genuchten, M.T. and G.J. Hoffman. 1984. Analysis of crop salt tolerance data, p. 258-271. In: I Shainberg and J. Shalhevet (eds.). Soil salinity under irrigation-Processes and management. Springer-Verlag, New York.

Waister, P.D. 1972. Wind damage in horticultural crops. Hort. Abstr. 42(3):609-615.

Watt, M.S., J.R. Moore, and B. McKinlay. 2005. The influence of wind on branch characteristics of Pinus radiata. Trees 19:58-65.
Stokes, A., A.H. Fitter, and M.P. Coutts. 1995. 